\title{
Co-development Ventures: Optimal Time of Entry and Profit-Sharing
}

\author{
Jakša Cvitanić *, Sonja Radas †and Hrvoje Šikić $\ddagger$
}

November 12, 2008

\begin{abstract}
We find the optimal time for entering a joint venture by two firms, and the optimal linear contract for sharing the profits. Our dataset shows that in practice, many contracts are based on fifty/fifty profit sharing. In our model, that happens in the following cases: symmetric information and contracts which include fixed cash payments; asymmetric information, fixed cash payments included, and comparable bargaining power of the two firms; asymmetric information, fixed cash payments excluded, and one firm perceives extra benefits from entering the venture. The model predicts that the less experienced firms are compensated more by royalties and less by equity, which is confirmed empirically in the dataset. Overall, the optimal time of entry is quite robust to model specifications, and the loss of utility of the firm with less information is not very significant when it can dictate the parameters of the linear contract.
\end{abstract}

Key words: Real Options; R\&D Projects; Joint Ventures; Optimal Contracts; Entry Time; Risk Sharing.

${ }^{*}$ Caltech, Humanities and Social Sciences, MC 228-77, 1200 E. California Blvd. Pasadena, CA 91125. Ph: (626) 395-1784. E-mail: cvitanic@hss.caltech.edu. Research supported in part by NSF grants DMS 0403575 and DMS 06-31298, and through the Programme "GUEST" of the National Foundation For Science, Higher Education and Technological Development of the Republic of Croatia. We are solely responsible for any remaining errors, and the opinions, findings and conclusions or suggestions in this article do not necessarily reflect anyone's opinions but the authors'.

${ }^{\dagger}$ The Institute of Economics, Zagreb, Trg J. F. Kennedy 7, 10000 Zagreb, Croatia. E-mail: sradas@eizg.hr.

${ }^{\ddagger}$ Department of Mathematics, University of Zagreb, Croatia. E-mail: hsikic@math.hr. Research supported in part by the MZOŠ grant 037-0372790-2799 of the Republic of Croatia 


\section{Introduction}

Innovation is a crucial factor for a company's survival and success, and co-development partnerships are an increasingly used way of improving innovation effectiveness. These partnerships are working relationships between two or more partners with the goal of creating and delivering a new product, technology or service (Chesbrough and Schwartz, 2007). While the traditional business model centers on a company which develops a new product in-house (from own R\&D) and then produces, markets and sells it using its own internal resources, the new model of open innovation includes co-development partnerships. In this way different partners' resources and capabilities can be optimally combined, thus creating significant reductions in R\&D expense and time to market. According to Quinn (2000), using co-development "leading companies have lowered innovation costs and risks by $60 \%$ to $90 \%$ while similarly decreasing cycle time and leveraging their internal investments by tens to hundreds of times".

At the same time, co-development expands the innovation output and helps companies reach new markets that may otherwise be inaccessible. The co-development is especially valuable in industries that are technology-based such as pharmaceuticals, software, computers, telecommunications, etc. Start-up firms that enter with new technologies and product ideas may be very interested in co-development arrangements, especially in those industries where it is more difficult to bring innovations to market. For a start-up the value of codevelopment is in access to resources it does not have, while for a large firm the value lies in harvesting existing innovation and thus extending its product portfolio. Although the

large firm may be very knowledgeable about technology, it will not have the project-specific knowledge possessed by the project originator (Pisano, 1997). This asymmetry is then dealt with through contractual terms that are designed to deter shirking, and through selection incentives, such as milestone payments, royalties and other contingent or back-loaded forms of payment to the licensor.

In this paper we focus on the co-development alliance between a firm which is the originator of the project or the new product idea, called firm $S$ (for "small") and a firm which provides research and other lacking resources necessary for product development, 
called firm $L$ (for "large"). We model the decision to enter co-development using real options theory. In particular we examine how time of entering the alliance depends on availability of information and bargaining power of firm $S$.

\subsection{Theoretical background}

There are three strands of literature related to our study. The first strand relates to firm alliances. In their quest for efficient operations, firms increasingly revert to inter-firm networking. In particular, in technology-based industries incumbent firms frequently form strategic alliances with smaller firms and new entrants (Gulati, 1998; Hagedoorn, 1993). According to Mariti and Smiley (1983), Harrigan (1985), Porter and Fuller (1986), and Hagedoorn and Schakenraad (1991), the main motives for collaboration between firms include sharing of costs/risks, access to partner's know-how, markets or products, efficiency enhancements (such as economies of scale in production, distribution or R\&D, and synergy effects from exchanging or sharing complementary know-how), competitive considerations (such as monitoring or controlling partner's technology, markets or products, influencing other alliance activities, and influencing competitive structure) and collaborating in order to take advantage of government policy (such as subsidies). In addition to all these, the new trend of collaborating with the aim to produce a technological innovation has been growing stronger (Veugelers, 1998). Large firms with hefty R\&D budgets and internal R\&D capabilities have actively used the "market for know-how" through contractual arrangements to acquire access to new technologies (Pisano, 1997), while small entrepreneurial firms seek alliances with large firms to avail themselves of the resources that are too costly, or too difficult to build internally. In this way, the partners in co-development can make best use of their combined complementary resources. In fact, extant research on the prevalence of motives suggests that exploiting complementarities is a major motive for cooperation in R\&D (Mariti and Smiley, 1983; Hagedoorn and Schakenraad, 1991). Teece (1986) finds that because of complementarities, the incumbent firm with competencies in marketing and manufacturing is well positioned to benefit from radical technological change introduced by new entrants. Complementary assets held by incumbents and used in interfirm alliances were found to be one of the vehicles of incumbents' survival in the face of radical technology 
change (Tripsas, 1997; Rothaermel, 2001).

The second strand of literature relates to the contractual arrangements in co-development alliances. Much of the economic modeling literature on company relationships is framed within an agency model (e.g. Bolton and Dewatripont, 2005; Crama et al., 2007), where asymmetric information and risk aversion are studied as sources of inefficiency. Regarding the form that co-development alliances can take, literature identifies two types: joint venture and contractual arrangements. Comino et al (2007) find that the presence of R\&D activities in the agenda makes it more likely that the alliances take the form of contractual agreements and this effect gets even stronger when the R\&D activities take place in technologically sophisticated sectors. This finding provides motivation for developing a real option theory of alliances. Contractual arrangements in such alliances usually involve up-front payments and royalties that protect prospective licensee from the risk; namely when the licensee estimates the risk to be high they can attempt to shift the balance of payments away from up-front fees toward future royalties on end sales and thus transfer the project risk toward the licensor (Pisano, 1997). Sometimes milestone payments are used for successfully reaching certain stages in product development. Such milestone and royalty contracts arising from asymmetric information have been studied in the literature, dealing with issues of risk sharing between the two firms (Amit et al., 1990), as well as adverse selection and moral hazard (Gallini and Wright, 1990; Crama et al., 2007). Adverse selection occurs because the product originator knows more about the technical characteristics of the product than the large firm, while moral hazard occurs because the product originator cannot verify how committed the large firm will be to the development of the product. Savva and Scholtes (2007) develop a theoretical model that shows how the effect of these inefficiencies can be resolved by allowing opt-out options for both parties.

The third and last strand of literature relates to the use of real options in modeling interfirm alliances. Real options framework recognizes that investment opportunities are options on real assets, and as such is able to provide a way to apply the theory of financial options to problems related to firm's investment decisions. Most extant literature considers the case of one firm's R\&D investment decision (Mitchell and Hamilton 1988; McGrath 1997; Folta 1998), timing of the investment (Henderson, 2007; Miao and Wang, 2006; Dixit 
and Pindyck, 1994), the development of organizational capabilities (Kogut and Kulatilaka 2001), and entry decisions (Miller and Folta 2002). Real options can be also used to model alliances. For example Kogut (1991) posits that joint ventures could be viewed as real options, where one of the partners can exercise the option to buy equity of the other partner and thus to expand in response to future market and technological developments. Reuer and Tong (2005) also investigate joint ventures using real options theory. Folta and Miller (2002) use real options to examine acquisition patterns by pharmaceutical firms in the biotechnology industry. The authors assume that when an established company holds a minority stake in a new biotechnology firm, that is equivalent to holding options on a future acquisition; they proceed to examine under which conditions the established firm is more likely to exercise the option and to acquire the biotechnology firm. Comino et al (2007) find that alliances that involve $R \& D$ (like co-development alliances) are more likely to take the form that can be described using the theory of real options. Ziedonis (2007) examines the use of options contracts by firms acquiring rights to commercialize university technologies, and finds that firms are more likely to purchase option contracts for more uncertain technologies, and the firms that are better able to evaluate an external technology are less likely to purchase options before licensing.

\subsection{Aims and contributions}

Our paper follows a real options approach in modeling the decision to form co-development alliance. Methodologically, we use the theory of the optimal stopping of diffusion processes. Classical references of its applications in economics include McDonald and Siegel (1986) and the book Dixit and Pindyck (1994), where this theory was shown to be extremely useful for problems involving real options, and in particular for the option of entering and/or exiting a project. For a very general recent mathematical treatment of such problems, see Johnson and Zervos (2008). The latter work also shows how to reduce mixed entry and exit problems with intertemporal profit/loss rate to standard optimal stopping problems, a "trick" we find useful in this paper, too.

Our methodological contributions consist of the following: (i) We add to the real options literature by modeling two companies deciding on entry time, instead of only one company 
performing the optimization over possible times of entry (the existing real options literature mostly deals with the latter case). When finding the optimal time of initiating a project, we consider first the case of symmetric information between the two firms, and we find the Pareto optimal time, that is we maximize a linear combination of the two firms' objectives. This can be interpreted in two ways, as maximizing the social welfare, but it is also the commonly accepted mechanism in contract theory for profit sharing between two economic agents with symmetric information. For a fixed value of a parameter representing the relative bargaining power, in addition to the optimal entry time, this procedure determines the optimal parameters of the contract. Thus, the actual level of sharing depends on the bargaining power. Next, we examine the case when information is asymmetric. In this case, it is standard to suppose that the firm with more information can choose from a menu of contracts, which will induce it to reveal the information. We assume that letting firm $S$ choose the timing will induce it to reveal indirectly the information it has. Thus, in our model the company with more information decides on the initiation time, while the other company decides on how to share the profits, while satisfying the participation constraint of the former company. (ii) We model the risk attitudes in more general terms than is typical. We assume that the companies are potentially risk averse, while in the literature they are usually risk neutral. However, we use flexible risk aversion functions which can approximate the case of risk-neutrality, as close as desired. In any case, qualitatively, the results are not very sensitive to the choice of risk aversion. (iii) The sufficient conditions of Johnson and Zervos (2008) are not satisfied in our model, so we prove from the scratch that the same method works. Basically, we show that the usual way of finding the optimal entry time works in a model in which the value of the project follows an arithmetic Brownian motion, while the risk preferences are described by exponential utility functions; or, equivalently from the mathematical point of view, the value of the project follows a geometric Brownian motion, while the risk preferences are described by power utility functions.

Our model allows us to determine optimal entry times and optimal linear contracts, and to explore how these differ between the cases of symmetric vs. asymmetric information. We also investigate the relationship between the optimal entry times, the parameters of the optimal contract and the relative bargaining power of the firms. The main theoretical findings 
are: (i) a number of model specifications results in the (approximately) equal percentage sharing of profits, consistent with the real life data in the pharmaceutical/biotechnology ventures in our dataset; (ii) the optimal time of entry is not overly sensitive to the model specifications; (iii) the utility loss of the firm with less information is not significantly larger than when the information is symmetric (for most values of the bargaining power); (iv) the firms with lower bargaining power are compensated more by royalties and less by equity (this is true both in the model and in the dataset); (v) changing the model parameters, and, in particular, the risk aversion parameters of the firms, does not change the above qualitative conclusions.

Section 2 describes the model and basic mathematical techniques for solving the entry problem in the presence of one firm only. In Section 3 we solve for the optimal linear contract between two firms, for symmetric and for asymmetric information case. We discuss comparative statics in Section 4, and in Section 5 we examine the agreement of those theoretical predictions with empirical facts implied from a dataset of real world alliances. Section 6 concludes.

\section{Method for finding the optimal entry time}

In this section we describe a methodology for finding the optimal entry time in a general formulation. The technique is familiar from the optimal stopping theory and its applications in the theory of real options, and has recently been analyzed in a very general context by Johnson and Zervos (2008). We follow closely their approach, but our special case does not satisfy their general assumptions, so we derive everything from the scratch. Moreover, our project may have a finite deterministic duration, while they have either infinite duration or an optimally chosen exit time.

There are two firms, $S$ (for "small") and $L$ (for "large"). We think of firm $L$ as a pharmaceutical company which wants to co-develop a new product jointly with its inventor, firm $S$, which is an $\mathrm{R} \& \mathrm{D}$ firm. After entering a co-development project at time $\tau$, they share future profit/loss up to time $\tau+T$. Here, $T$ is the time horizon, and all the results hold for $T=\infty$, too. The profit/loss process is a function of the state process $X$, following 
a Stochastic Differential Equation (SDE)

$$
d X_{t}=b X_{t} d t+\sigma X_{t} d W_{t}
$$

where $b, \sigma$ are constants and $W$ is a Brownian motion process.

Let us consider the problem of when to enter the project from a point of view of one decision maker. All our problems will reduce to this case, as we will either have to maximize the combined objectives of the two firms when they have the same information, or else, in the case of asymmetric information, only one firm will be making the entry decision.

By definition, the optimal entry time is obtained by maximizing over stopping times $\tau$ an expression of the form

$$
E_{x}\left[\mathbf{1}_{\{\tau<\infty\}}\left(\int_{\tau}^{\tau+T} e^{-r t} h\left(X_{t}\right) d t+e^{-r \tau} h_{1}\left(X_{\tau}\right)\right)\right]
$$

Here, $r$ is a discount rate, $h\left(X_{t}\right)$ will represent the utility (or a combination of utilities of two firms) obtained from the future profit/loss rate, and $h_{1}\left(X_{t}\right)$ is initial utility (or a combination of utilities). Although our main methodological theorem in Appendix covers a more general case, in this paper we will only consider functions $h, h_{1}$ of the form

$$
h(x)=\sum_{i=1}^{I}\left[k_{i}+l_{i} x^{\gamma_{i}} / \gamma_{i}\right], \quad h_{1}(x)=\sum_{i=1}^{I}\left[k_{1, i}+l_{1, i} x^{\gamma_{i}} / \gamma_{i}\right]
$$

Note that these are linear combinations of concave increasing functions, where $\gamma_{i}<1$ will reflect the degree of risk aversions. ${ }^{1}$

Denote

$$
\begin{gathered}
\beta:=2 b / \sigma^{2} \\
n:=1 / 2-\beta / 2+\sqrt{(\beta / 2-1 / 2)^{2}+2 r / \sigma^{2}}
\end{gathered}
$$

and

$$
\theta_{i}:=\theta\left(\gamma_{i}\right)=r-\gamma_{i}^{2} \sigma^{2} / 2-\gamma_{i}\left(b-\sigma^{2} / 2\right)
$$

\footnotetext{
${ }^{1}$ We could have a different number of terms in the two sums by having some of the coefficients equal to zero.
} 
We assume throughout this paper that

$$
r>b
$$

This implies $n>1$, and guarantees that the optimization problem does not explode when $T=\infty$. Moreover, we also assume that

$$
l_{i}+l_{1, i} \geq 0,
$$

that at least one of the terms $\left[l_{i}+l_{1, i}\right]$ is strictly positive, and that, for those $i$ with $\left[l_{i}+l_{1, i}\right]>0$ we have that all $\gamma_{i}$ are of the same sign and

$$
\gamma_{i} \sum_{j}\left[k_{j}^{r}+k_{1, j}\right]<0, \quad \theta_{i}>0
$$

These inequalities will guarantee that it is not optimal to start at time zero, and that it is not optimal never to enter the project. ${ }^{2}$

Denote

$$
R_{h}(x):=E_{x} \int_{0}^{T} e^{-r s} h\left(X_{s}\right) d s
$$

We show in Lemma 7.1 in Appendix that the problem of maximizing (2.1) is equivalent to the maximization problem

$$
w(x):=\sup _{\tau} E_{x}\left[\mathbf{1}_{\{\tau<\infty\}} e^{-r \tau}\left[R_{h}\left(X_{\tau}\right)+h_{1}\left(X_{\tau}\right)\right]\right]
$$

We can compute

$$
R_{h}(x)=\sum_{i}\left[k_{i}^{r}+l_{i}^{\theta_{i}} \frac{x^{\gamma_{i}}}{\gamma_{i}}\right]
$$

where

$$
\begin{aligned}
& k_{i}^{r}=k_{i} \frac{1-e^{-r T}}{r} \\
& l_{i}^{\theta_{i}}:=l_{i} \frac{1-e^{-\theta_{i} T}}{\theta_{i}}
\end{aligned}
$$

\footnotetext{
${ }^{2}$ It is not hard to construct examples, for example with $I=1$, which show that if these conditions are not satisfied, we can have optimal $\tau$ equal to zero or infinity.
} 
Denote also

$$
g(x):=R_{h}(x)+h_{1}(x)
$$

We can then write

$$
g(x)=\sum_{i=1}^{I}\left[k_{i}^{r}+k_{1, i}\right]+\sum_{i=1}^{I}\left[l_{i}^{\theta_{i}}+l_{1, i}\right] x^{\gamma_{i}} / \gamma_{i}
$$

According to Theorem 7.1 and subsection 7.1 in Appendix, the optimal time of entry is the first time process $X$ hits the point $\hat{x}$ that is determined from the equation

$$
n g(\hat{x})=\hat{x} g^{\prime}(\hat{x})
$$

or

$$
\sum_{i}\left[k_{i}^{r}+k_{1, i}\right]=\sum_{i=1}^{I}\left[l_{i}^{\theta_{i}}+l_{1, i}\right]\left(\frac{1}{n}-\frac{1}{\gamma_{i}}\right) \hat{x}^{\gamma_{i}}
$$

We will be solving this equation numerically, except in the case $I=1 \mathrm{in}$ which it is easily verified that

$$
\hat{x}^{\gamma}=\gamma \frac{\theta}{l+l_{1} \theta} \frac{k / r+k_{1}}{\gamma / n-1}
$$

Remark 2.1 For $\gamma<0$, write

$$
\frac{1}{\gamma} x^{\gamma}=\frac{1}{\gamma} e^{\gamma \log (x)}
$$

Then, we can interpret $\log \left(X_{t}\right)$ as the profit/loss rate, and $e^{\gamma x} / \gamma$ as a utility function, and we can still use all the results from above. This is exactly what we will do next.

\section{Profit/Risk sharing: optimal contracts between two firms}

In addition to deciding on the time of entry, the two firms have to decide how to share the profits/losses. We will consider two cases, symmetric and asymmetric information.

\subsection{Symmetric information: maximizing joint welfare}

Denote by $P_{t}=P\left(X_{t}\right)$ the total profit/loss rate to the two firms $S$ and $L$, and by $U_{L}$, $U_{S}, u_{L}, u_{S}$, the utility functions of the firms. For a given $\lambda>0$, the profit-sharing, or the risk-sharing problem with symmetric information is to maximize, over entry time $\tau$, initial 
payoff $C_{\tau}$ and payment rate $c_{t}$ from firm $L$ to firm $S$, the value

$$
E_{x}\left[\mathbf{1}_{\{\tau<\infty\}}\left(\int_{\tau}^{\tau+T} e^{-r t}\left[U_{L}\left(P_{t}-c_{t}\right)+\lambda U_{S}\left(c_{t}\right)\right] d t+e^{-r \tau}\left[u_{L}\left(P_{\tau}-C_{\tau}\right)+\lambda u_{S}\left(C_{\tau}\right)\right]\right)\right]
$$

In other words, we maximize a weighted sum of the expected utilities of the two firms, where the weight $\lambda$ is interpreted as the bargaining power of firm $S$ relative to firm $S$. This is the standard contract theory approach for finding optimal contracts between two entities in the case of symmetric information (see Bolton and Dewatripont 2005).

By maximizing inside the integral with respect to $c_{t}$, we see that the first order condition for optimality of $c_{t}$ is the classical Borch (1962) condition for risk sharing:

$$
U_{L}^{\prime}\left(P_{t}-c_{t}\right)=\lambda U_{S}^{\prime}\left(c_{t}\right)
$$

The optimal payment $c_{t}$ from the $L$ to $S$ is the solution to this equation. In particular, if the utility functions are exponential,

$$
U_{i}(x)=k_{i}+\frac{l_{i}}{\gamma_{i}} e^{\gamma_{i} x}
$$

then the optimal $c_{t}$ is linear,

$$
c_{t}=c+a P_{t}
$$

for constants

$$
a=\frac{\gamma_{L}}{\gamma_{L}+\gamma_{S}}, \quad c=-\log \left(\lambda l_{S} / l_{L}\right) /\left(\gamma_{L}+\gamma_{S}\right)
$$

Completely analogous discussion holds for the initial payment $C_{\tau_{1}}$. In particular, if we assume $u_{i}(x)=k_{i 1}+\frac{l_{i 1}}{\gamma_{i}} e^{\gamma_{i} x}$, then a linear initial contract $C_{\tau}=c_{1}+a P_{\tau}$ is optimal, with $c_{1}=-\log \left(\lambda l_{S 1} / l_{L 1}\right) /\left(\gamma_{L}+\gamma_{S}\right)$.

In this derivation, there are no limited liability constraints, that is, there is no lower bound on the payments. Thus, $c_{t}$ and $C_{\tau}$ may take negative values, and firm $S$ may have to pay cash payments to the large firm. That rarely, if ever, happens in practice. One not 
unreasonable way to avoid that, is to posit that only the contracts of the form

$$
c_{t}=a P_{t}, \quad C_{\tau}=a_{1} P_{\tau}
$$

are used. This may be justified by the fact that most of the compensation is based on future royalties plus milestone payments, and on initial cash plus equity payment. More precisely, we can consider contracts of the form (3.9) with the interpretation that the royalties, milestone payments and possibly the additional investments of firm $S$ into the project are lumped together into $c_{t}=a P_{t}$, while the initial cash plus equity is represented by $C_{\tau}=a_{1} P_{\tau}$. The justification for the latter comes from the empirical fact that the size of the initial cash amount observed in the data depends on the phase of the product, thus it is not unappropriate to model it as proportional to process $P_{t}$. After concentrating our attention first to the simple payments as in (3.9), we then will perform also a maximization allowing non-zero cash payments $c$ and $c_{1}$, for the contracts of the form

$$
c_{t}=a P_{t}+c, \quad C_{\tau}=a_{1} P_{\tau}+c_{1}
$$

For the payments as in (3.9), the problem of obtaining the Pareto optimal risk-sharing is to maximize

$$
\begin{aligned}
V_{P}:= & E_{X_{0}}\left[\mathbf{1}_{\{\tau<\infty\}} \int_{\tau}^{\tau+T} e^{-r t}\left[U_{L}\left((1-a) P_{t}\right)+\lambda U_{S}\left(a P_{t}\right)\right] d t\right] \\
& +E_{X_{0}}\left[\mathbf{1}_{\{\tau<\infty\}} e^{-r \tau}\left[u_{L}\left(\left(1-a_{1}\right) P_{\tau}\right)+\lambda u_{S}\left(a_{1} P_{\tau}\right)\right]\right]
\end{aligned}
$$

Here, we take $P_{t}=\log \left(X_{t}\right)$ and the utility functions as

$$
U_{i}(x)=k_{i}+\frac{l_{i}}{\gamma_{i}} e^{\gamma_{i} x}, u_{i}(x)=k_{i 1}+\frac{l_{i 1}}{\gamma_{i}} e^{\gamma_{i} x}, \quad i=S, L
$$

Denote

$$
g\left(x, a, a_{1}\right)=k_{L}^{r}+\lambda k_{S}^{r}+k_{L, 1}+\lambda k_{S, 1}+l_{L}^{\theta\left([1-a] \gamma_{L}\right)} \frac{x^{[1-a] \gamma_{L}}}{\gamma_{L}}+l_{1, L} \frac{x^{\left[1-a_{1}\right] \gamma_{L}}}{\gamma_{L}}+\lambda l_{S}^{\theta\left(a \gamma_{S}\right)} \frac{x^{a \gamma_{S}}}{\gamma_{S}}+\lambda l_{1, S} \frac{x^{a} \gamma_{1} \gamma_{S}}{\gamma_{S}}
$$


Let the time of entry $\tau$ be the first time process $X$ hits a value $x$. From the standard results on Brownian hitting times, we get, for $X_{0} \leq x$,

$$
E_{X_{0}}\left[\mathbf{1}_{\{\tau<\infty\}} e^{-r \tau}\right]=\left(\frac{X_{0}}{x}\right)^{n}
$$

Thus, from (2.2), the expression in (3.11) is given by

$$
V_{P}\left(a, a_{1}, x\right)=g\left(x, a, a_{1}\right)\left(\frac{X_{0}}{x}\right)^{n}
$$

We will maximize this numerically over $\left(a, a_{1}, x\right) \in[0,1] \times[0,1] \times \mathbf{R}^{+}$. We will also compute the expected utilities of the firms $S$ and $L$. Denote

$$
\begin{gathered}
g_{S}\left(a, a_{1}, x\right)=\left[k_{S}^{r}+k_{S, 1}\right]+l_{S}^{\theta\left(a \gamma_{S}\right)} \frac{1}{\gamma_{S}} x^{a \gamma_{S}}+l_{1, S} \frac{1}{\gamma_{S}} x^{a_{1} \gamma_{S}} \\
g_{L}\left(a, a_{1}, x\right)=\left[\frac{k_{L}}{r}+k_{L, 1}\right]+l_{L}^{\theta\left([1-a] \gamma_{L}\right)} \frac{1}{\gamma_{L}} x^{[1-a] \gamma_{L}}+l_{1, L} \frac{1}{\gamma_{L}} x^{\left[1-a_{1}\right] \gamma_{L}}
\end{gathered}
$$

Then, the corresponding expected utilities are given by

$$
\begin{gathered}
V_{S}\left(\hat{a}, \hat{a}_{1}, \hat{x}\right)=g_{S}\left(\hat{a}, \hat{a}_{1}, \hat{x}\right)\left(\frac{X_{0}}{\hat{x}}\right)^{n} \\
V_{L}\left(\hat{a}, \hat{a}_{1}, \hat{x}\right):=g_{L}\left(\hat{a}, \hat{a}_{1}, \hat{x}\right)\left(\frac{X_{0}}{\hat{x}}\right)^{n}
\end{gathered}
$$

where $\left(\hat{a}, \hat{a}_{1}, \hat{x}\right)$ are optimal for maximizing $V_{P}\left(a, a_{1}, x\right)$.

Similar computations can be done in case of the contracts as in (3.10).

\subsection{Asymmetric information: firm $S$ decides on entry time, firm $L$ de- cides on payoff structure}

We now assume that firm $S$ decides on the starting time of the joint venture, while firm $L$ decides on the form of the contract payoff. An economic interpretation is the following: suppose firm $S$ has information about the quality of the product which is not revealed to firm $L$ until they start the joint venture. In this case the standard contract theory approach is that firm $S$ with more information can choose from a menu of contracts, each one aimed 
at a firm $S$ with a specific quality of the product. Moreover, the contracts in the menu are structured so that firm $S$ reveals the product's quality (this is called the "revelation principle", see Bolton and Dewatripont 2005). We assume that letting firm $S$ decide when to start the venture will induce it not to misrepresent the quality. Arguably, in practice it is, indeed, often firm $S$ which decides when to "put itself on the market". In accordance with the above assumptions, at the moment $\tau$ of initiating the joint venture, we suppose that the quality of the project is revealed to firm $L$, that is, $X_{\tau}$ and the parameters $b$ and $\sigma$ are known. However, firm $L$ does not know whether firm $S$ has been waiting, or whether it just has completed the product in a manner suitable for co-development. Consistent with this, we assume that the contract cannot penalize firm $S$ for having waited.

Moreover, again in accordance with the standard contract theory approach, we suppose that firm $L$, that is, the firm with less information, decides on the form of the contract payoff, i.e. on the structure of the menu of contracts. We assume exponential utility functions as above, and again we first consider the contract payoffs of the linear form,

$$
c_{t}=a P_{t}, \quad C_{\tau}=a_{1} P_{\tau}
$$

Firm $L$ has to choose $a$ and $a_{1}$ maximizing her utility while satisfying the "participation constraint" that firm $S$ 's utility has to be no less than a given constant $R$ ("reservation utility"), which may depend on the revealed $X_{\tau}, b, \sigma$.

So, suppose that firm $S$ can expect the contract as above, given that it will be revealed that the quality is $\left(X_{\tau}, b, \sigma\right)$. Thus, firm $S$ maximizes, over stopping times $\tau$,

$$
V_{S}(\tau):=E_{x}\left[\mathbf{1}_{\{\tau<\infty\}}\left(\int_{\tau}^{\tau+T} e^{-r t} U_{S}\left(a P_{t}\right) d t+e^{-r \tau} u_{S}\left(a_{1} P_{\tau}\right)\right)\right]
$$

From Theorem 7.1 in Appendix it is easy to check that the optimal starting point $x_{S}$ is determined as a solution $x=x_{S}$ to

$$
\frac{k_{S}}{r}+k_{S, 1}=l_{S}^{\theta\left(a \gamma_{S}\right)}\left(\frac{a}{n}-\frac{1}{\gamma_{S}}\right) x^{a \gamma_{S}}+l_{1, S}\left(\frac{a_{1}}{n}-\frac{1}{\gamma_{S}}\right) x^{a_{1} \gamma_{S}}
$$


Recall that the utility of firm $L$ is given by

$$
V_{L}\left(a, a_{1}, x_{S}\right)=g_{L}\left(x_{S}\right)\left(\frac{X_{0}}{x_{S}}\right)^{n}
$$

For a given fixed $R$, firm $L$ needs to maximize $V_{L}$ over $\left(a, a_{1}, x_{S}\right)$ so that the constraint (3.14) is satisfied, and so that the firm $S$ utility $V_{S}$, given by (3.13), is no smaller than $R$. We report on the conclusions coming from our numerical computations in a section below, as well as on the case when the payments are of the form (3.10).

\subsection{Value of the option to enter the project}

Our framework provides also a way of deciding the value of the option to enter the project, which we sketch now. Since our firms are risk averse, we use the concept of certainty equivalent to determine that value. Consider a firm whose utility $V(x)$, where $x=X_{0}$, can be written as

$$
V(x)=E_{x}\left[\mathbf{1}_{\{\tau<\infty\}}\left(\int_{\tau}^{\tau+T} e^{-r t} U\left(P_{t}\right) d t+e^{-r \tau} u\left(P_{\tau}\right)\right)\right]
$$

Define the constant rate of payments $q$ and value $p$ such that

$$
\begin{gathered}
U(q) \frac{1-e^{-r T}}{r}=E_{x}\left[\mathbf{1}_{\{\tau<\infty\}} \int_{\tau}^{\tau+T} e^{-r t} U\left(P_{t}\right) d t\right] \\
u(p)=E_{x}\left[\mathbf{1}_{\{\tau<\infty\}} e^{-r \tau} u\left(P_{\tau}\right)\right]
\end{gathered}
$$

In other words, if we replaced $P_{t}$ with a constant $q$, and if the starting time was zero, the firm would be getting the same utility from the integral part as under the actual dynamics of $P$ and the actual starting time. Similarly for the initial utility. Then, we introduce the value of the option to enter the project, denoted $v$, as

$$
v=q \frac{1-e^{-r T}}{r}+p
$$

This procedure can be used for valuing projects of the type we study in this paper. 


\section{Comparative Statics}

Having developed the above framework, we can now compute the optimal entry points and the optimal contract for various parameters of the model. Our benchmark case has the following parameters, in annual terms:

$$
X_{0}=0.1, \gamma_{S}=\gamma_{L}=-1, r=0.1, b=0.07, \sigma=0.35, T=5,1=k_{i}=l_{i}=k_{i, 1}=l_{i, 1}
$$

In particular, the two firms have the same risk aversions in the computations, unless we say otherwise. The choice of parameters $r, b, \sigma$ and $T$ is in agreement with the real world examples. The choice of $X_{0}=1$ is a normalization, as is the choice of $l_{i}, l_{i 1}$. The values of $k_{i}, k_{i 1}$ are chosen so that the utility of zero profit is zero, the same as if never entering the venture. The choice of the risk aversions $\gamma_{i}$ is quite arbitrary, but it turns out that the main qualitative conclusions are not sensitive to the values of these parameters, as reported below.

All the graphs have $\log \lambda$ as the variable on the $x$-axis, where $\lambda$ is the "bargaining power" parameter from the symmetric information problem (3.11). When we deal with the asymmetric information case, we need to fix reservation utility $R$ of firm $S$, and we take those values of $R=R(\lambda)$ that come from the computations in the symmetric information case.

\subsection{Case I: symmetric information}

Figure 1 shows the required initial profit rate level $\log X_{\tau}$ for the Pareto optimal case of maximizing the joint welfare under symmetric information as in (3.11), and also when each firm optimizes its own utility. 


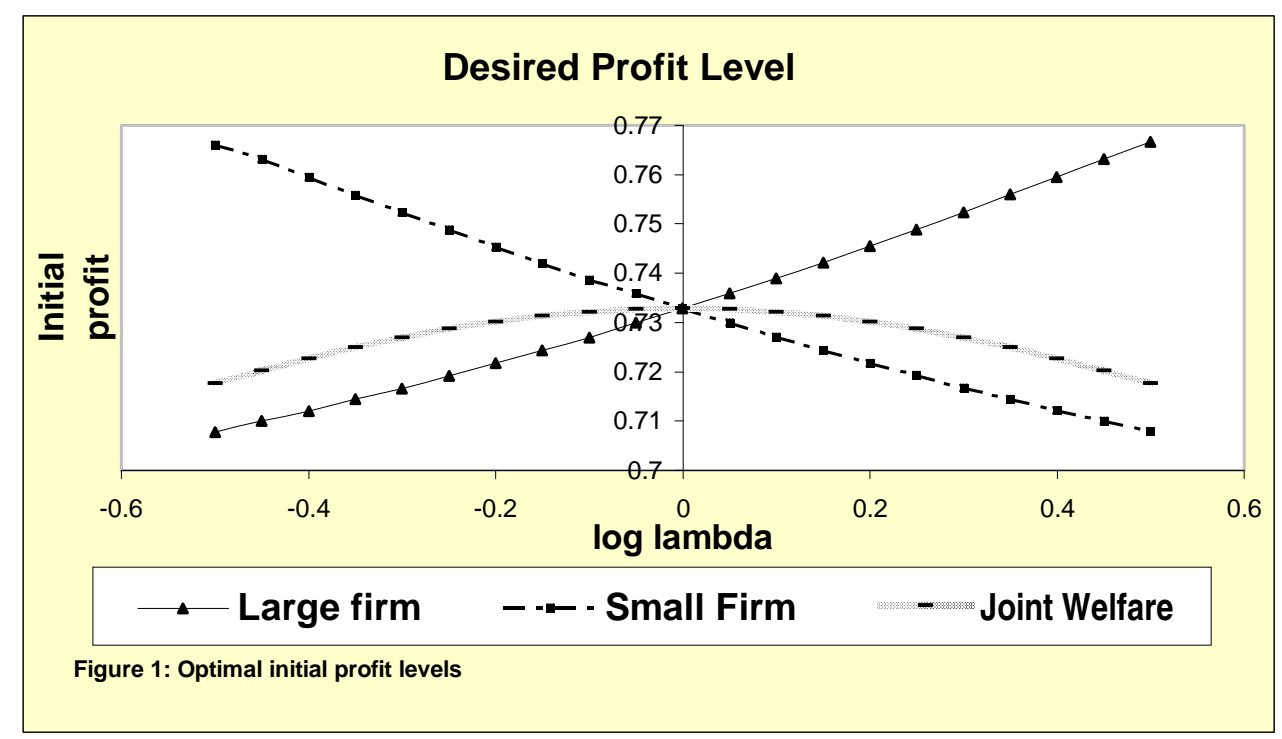

With larger bargaining power, that is, larger $\lambda$, firm $S$ fares better and thus wants to enter the co-development earlier, while firm $L$ wants to wait. Smaller $\lambda$ favors firm $L$ which therefore wants to enter early, while firm $S$ prefers to wait. The initial optimal profit rates when own expected utility is maximized are different for firm $S$ and firm $L$, and the initial profit rate optimal for joint welfare takes a compromise value between the two. In case of equal bargaining power $(\log (\lambda)=0)$, firm $S$ and firm $L$ agree on the same initial profit rate and therefore on the same time of entry into the alliance. This is also the Pareto optimal time which guarantees optimal joint welfare.

Next, we investigate the properties of the contract defined by "royalty" percentage $a$ and upfront, "equity" percentage $a_{1}$. (Let us recall the interpretation of $a_{1}$, which, in addition to equity, may include cash payments proportional to the phase of the project.) The symmetric information case, with no fixed cash payments allowed, is shown in Figure 2 . 


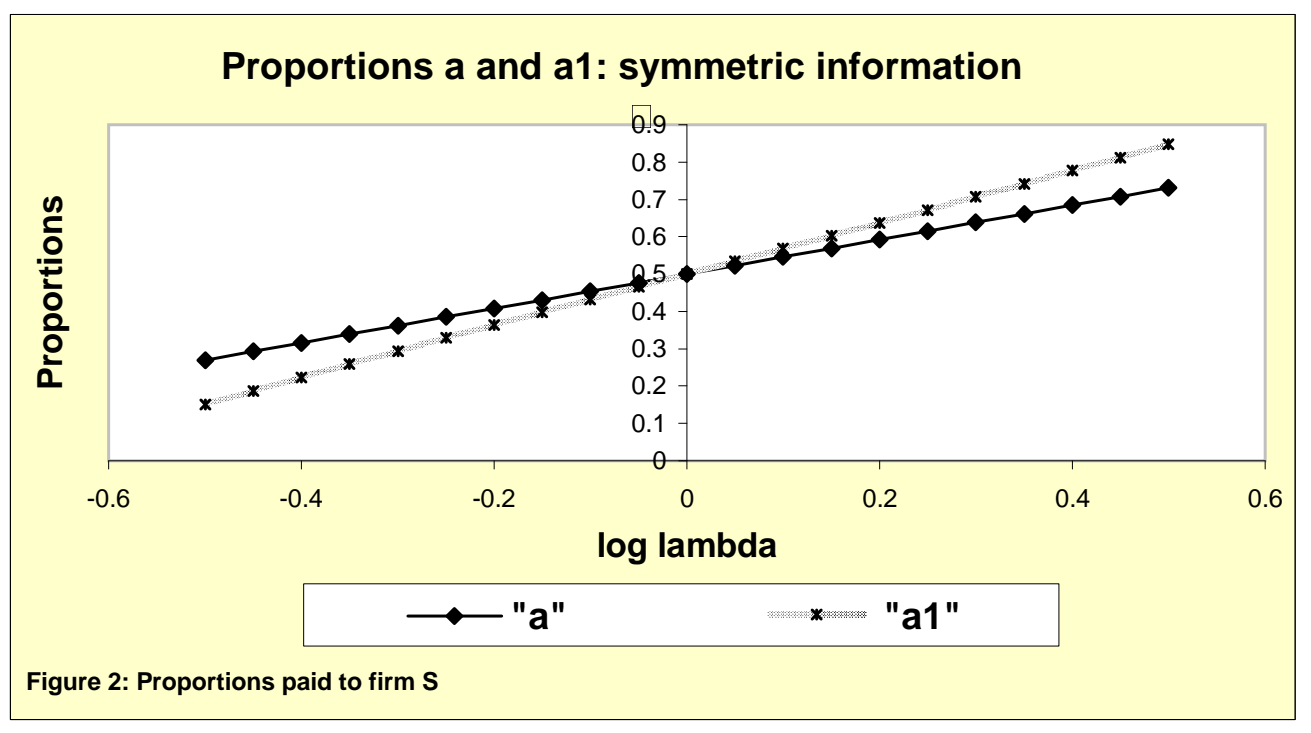

Both the royalty and the equity percentage payment become larger as the bargaining power of firm $S$ increases. We find that when the bargaining power of firm $S$ is low, the equity percentage payment should be lower than royalty (i.e. $a_{1}<a$ ), and when firm $S$ has high bargaining power, the equity percentage payment should be higher than royalty (i.e. $\left.a_{1}>a\right)$. Thus for a firm with very small bargaining power which can share information perfectly (probably at the very early stage of development), we would expect to see that it is compensated mostly by payment in royalties and that it is receiving low equity payment. This is, indeed, confirmed empirically by the data, as we report later in Section 5 .

The case when the fixed cash payments (corresponding to parameters $c$ and $c_{1}$ ) are allowed is shown in Figure 7 below.

\subsection{Case II: asymmetric information}

As discussed above, symmetric information is not very likely in the real world co-development decisions. The project originator, firm $S$, typically has more information about the project than the partner firm $L$. Therefore, we consider implications of our model in the situation of asymmetric information where firm $L$ decides on the contract form, while firm $S$ decides on when to enter the alliance. We again assume that both firms have the same risk aversion, and the same parameters as above. 


\subsubsection{No fixed cash payments}

First, we consider the contracts of the form

$$
c_{t}=a P_{t} \quad C_{\tau}=a_{1} P_{\tau}
$$

We look at how large is relative loss in expected utility of firm $L$, relative to the case of symmetric information, if we fix the expected utility of firm $S$ at the same level as in the case of symmetric information.

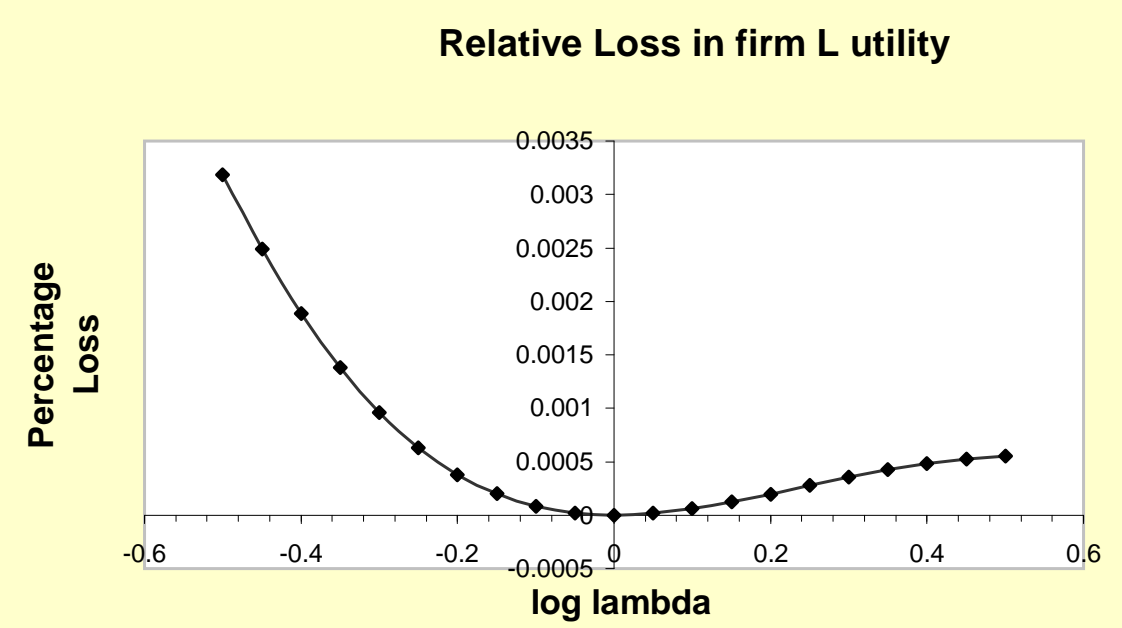

Figure 3: Relative utility loss for firm $L$ with asymmetric information.

The relative loss is presented in Figure 3, and we can see there is an asymmetry, it is higher when the bargaining power of firm $S$ is low than when it is high, and it is very low for comparable bargaining powers (in fact, there is no loss when the bargaining powers are the same). Overall, however, the percentage utility loss of firm $L$ due to asymmetric information is not very high.

We also look, in Figure 4, at the ratio of the (exponential of) required initial profit rate $x_{S}$, which firm $S$ chooses when the information is asymmetric, and the (exponential of) compromise initial profit rate from the symmetric information case. 


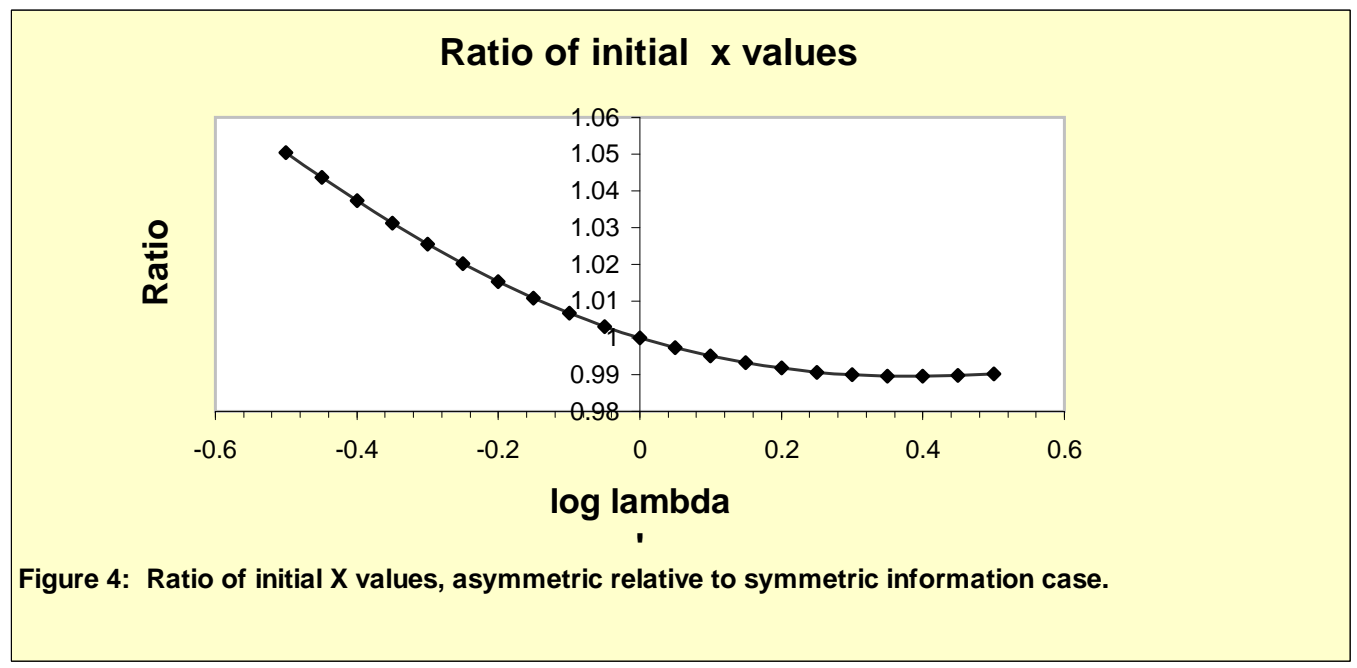

We observe that, when its bargaining power is high, firm $S$ tends to enter earlier, relative to the case of perfect information, and vice-versa when its bargaining power is low. However, overall the change in the starting point is not very significant - the time of entry is similar to the one with symmetric information.

When information becomes asymmetric, the optimal choice of $a$ and $a_{1}$ is qualitatively the same as with symmetric information, as shown in Figure 5.

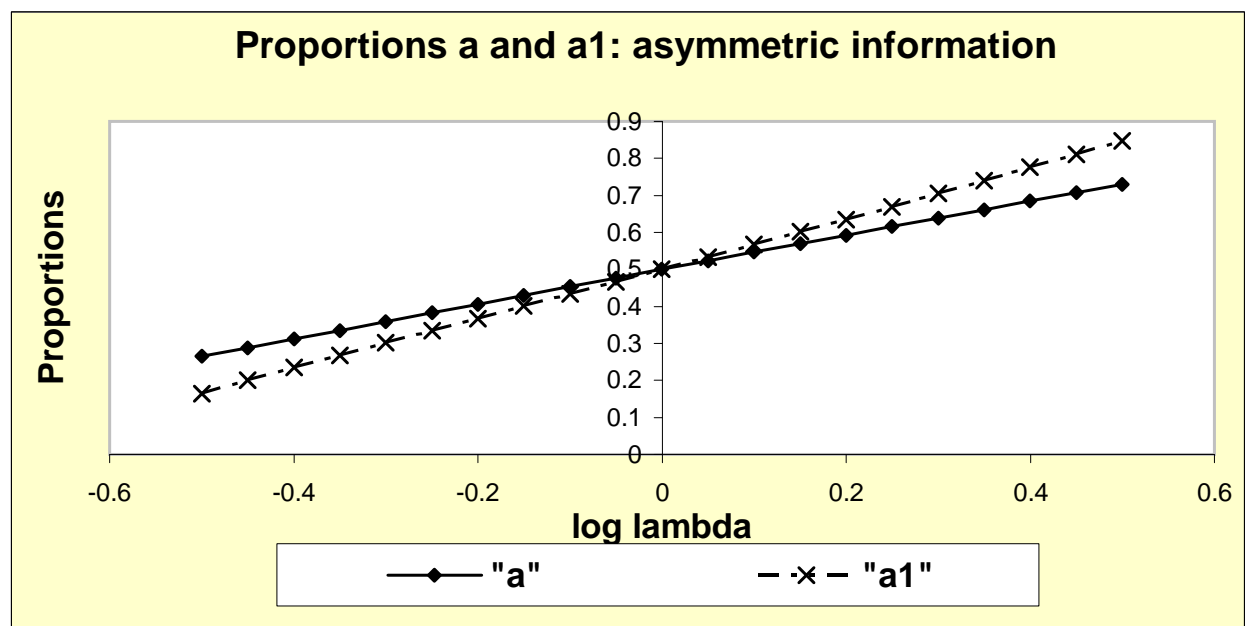

Figure 5: Proportions paid to firm S.

One difference is that the slope is smaller, that is, the percentages paid to firm $S$ are less sensitive to its bargaining power in the presence of asymmetric information.

For completeness, we now report on the comparative statics we obtained when varying different parameters. We save on space and provide no graphs here, the reason being that 
the effects of changing the parameters are not very significant.

Varying $b$. It has been stated that project quality is one of the crucial factors in decision to enter co-development (Pisano, 1997). Thus, we explore how project quality measured by $b$ impacts the terms of the contract (i.e. $a$ and $a_{1}$ ), in the benchmark case. We find that overall $a$ and $a_{1}$ do not change much when project quality $b$ changes, which indicates that the contract offered is quite robust to the project quality. What changes is the time of entry - firm $S$ enters later with higher $b$, waiting for the level of initial profits to reach a higher level. However, the relative ratio of initial entry levels between symmetric and asymmetric information case does not change much with project quality $b$, although, with asymmetric information, with higher $b$ firm $S$ waits a bit longer, relative to the symmetric information case, when it has low bargaining power, and waits relatively less with high bargaining power.

Although these effects are small in magnitude, their existence is not inconsistent with the lemon hypothesis from Pisano (1997). Pisano postulates that market for co-development projects functions in a similar way as the market for used cars described by Akerloff (1970) where asymmetric information and presence of low quality products drive everyone's price down to the level where only bad products remain in the market. In the co-development situation the inability of the licensor partner to accurately assess the project quality should cause only low quality projects to become collaborative and good quality projects to be retained and subsequently developed by the idea originator alone. Our model shows that the idea originator indeed may have a good reason for being reluctant to join forces with another firm when information is asymmetric and its bargaining power is low: in that case the firm with a high quality project optimally waits longer.

Varying $\sigma$. Qualitatively, no big changes occur. As could be expected, higher $\sigma$ means waiting longer to enter. Proportions $a$ and $a_{1}$ get less steep, higher on the low bargaining power side, and lower on the high side.

Varying risk aversions $\gamma_{i}$. Again, qualitatively, no big changes occur. As could be expected, with higher risk aversion $\gamma_{S}, a$ and $a_{1}$ become lower, and the time of entry is later. 
Varying $k_{S}$. In the benchmark case that we discussed up to now we chose the parameters so that the utility of receiving zero profits is equal to zero, which is also the utility of never entering the project. However, in reality there might be extra costs or extra benefits of being involved in the project, other than the pure profit/loss flow. For example, Nicholson et al (2003) find that inexperienced biotech companies tend to sign the first deals with large pharma companies on terms that are less than optimal for them, but the deal itself acts as a signal to potential investors and the rest of the community about the quality of the project and the company. The discount in the deal can be considered as a payment to the pharma company for the evaluation that it performs. Although the value of the project itself is sometimes difficult to disclose fully, the quality of the project-originating firm is easier to communicate. In the current model, when information is asymmetric, firm $S$ with low bargaining power tends to wait relatively longer to enter the alliance, and more so when it is of high quality. This actually supports the argument by Nicholson et al (2003), as firm $S$ would benefit from revealing the information in order to get better future deals by signaling quality through the alliance. We can model this situation assuming that firm $S$ achieves extra utility from entering the alliance, for example through the change of the values of $k$ and $l$-type parameters in the utility functions. One such case is depicted in Figure 6 , where $k_{S}$ is higher than the benchmark value. Figure 6 shows that in that case contracts with "sticky" royalties happen. By sticky royalties we mean those royalties that vary in a narrow range.

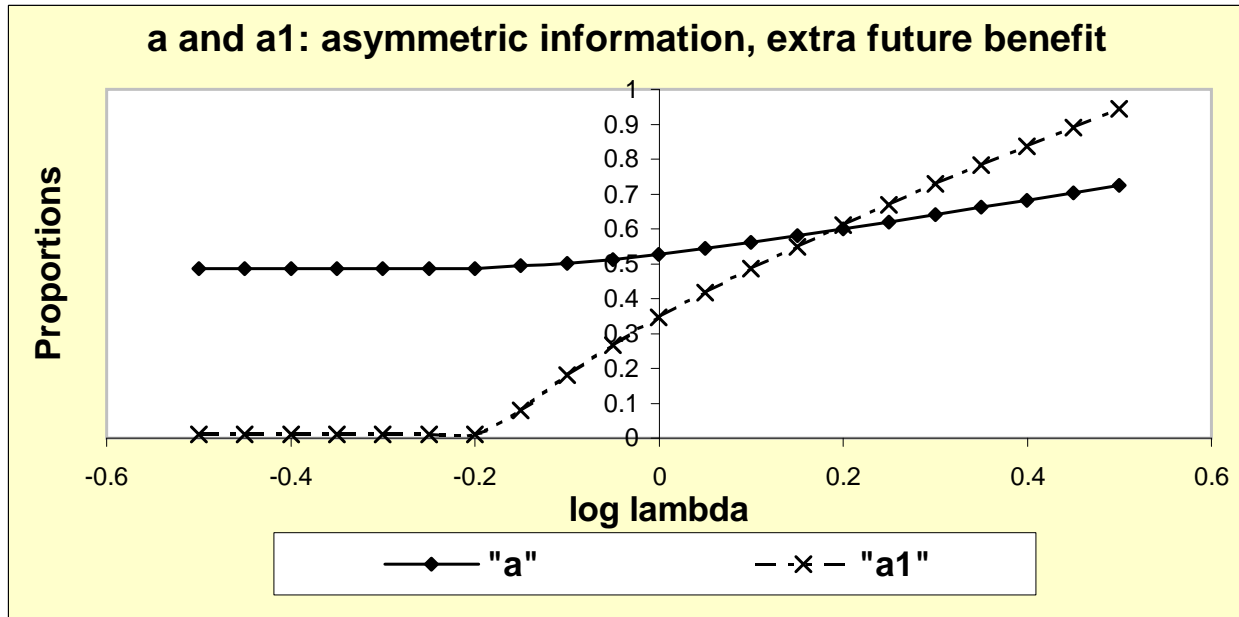

Figure 6: Proportions paid to firm $S$ when "k_S"=1.19 
We see that with this higher value of $k_{S}$ both royalties and equity payments do not vary much when firm $S$ bargaining power is low. This means that the contract offered by firm $L$ will be almost the same for partner firms with different degrees of bargaining power, as long as the latter is low. The percentage from the future income (royalty $a$ ) hovers around $50 \%$, while the percentage of the current value of the firm (equity payment $a_{1}$ ) starts at zero and stays there for a while. We examine below the agreement of these theoretical predictions with real data.

Unlike in the benchmark case, firm $S$ perceives a greater benefit of creating a partnership, and, because of that, it enters the joint venture very early (the values of required profit $\log x_{S}$, not reported, are quite lower than in the benchmark case). Because of the perceived high benefit for firm $S$, it is easier for firm $L$ to satisfy the participation constraint of firm $S$, that is, to pay at least the reservation wage. In fact, for low bargaining power of firm $S$, firm $L$ is willing to pay more than the reservation wage, by pushing up the value of $a$ to around $50 \%$ (while keeping $a_{1}$ at or close to zero). Thus the participation constraint is not actually binding in this range, and the optimum clusters around similar values of $a$ and $a_{1}$ (and $x_{S}$, not reported). With higher bargaining power, however, the reservation wage binds, and the higher utility for firm $S$ comes mostly from a sharp increase in equity payments.

\subsubsection{Fixed cash payments included}

It can be argued that the contracts of the type $c_{t}=a P_{t}, C_{\tau}=a_{1} P_{\tau}$ may not be the most efficient theoretically. Instead it would be more efficient to have contracts of the form

$$
c_{t}=a P_{t}+c \quad C_{\tau}=a_{1} P_{\tau}+c_{1}
$$

with $c$ representing the future cash payments, and $c_{1}$ representing the initial cash payment. We do that next.

For the case (4.15), we present the optimal values in Figure 7, with symmetric information, and in Figure 8, with asymmetric information. 


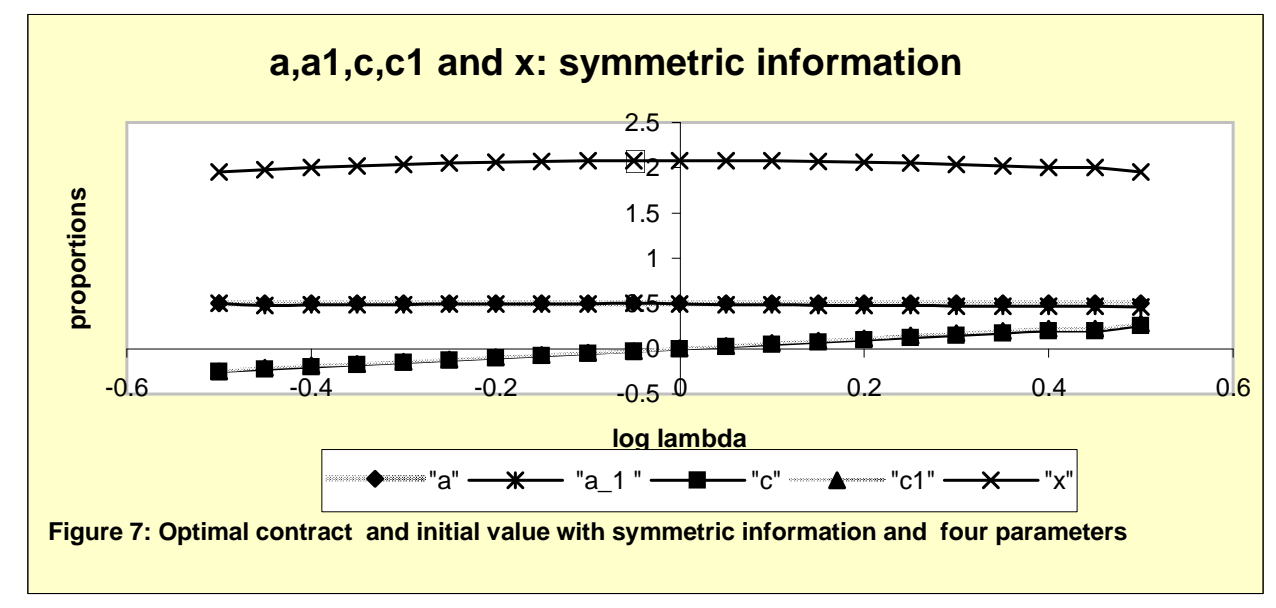

With symmetric information, we observe the following. Percentages $a$ and $a_{1}$ are almost the same, and always around $50 \%$. Cash payments $c$ and $c_{1}$ are also almost the same, and they increase, starting from negative values for low bargaining power of firm $S$. The negative values mean that firm $S$ pays. For example, it could be required to invest certain amount of cash in the co-development, for instance by paying salaries of additional employees. On the other hand, in addition to compensating firms $S$ with cash, firm $L$ could be investing some of its resources (people, equipment) into the project, which would be an example of positive $c, c_{1}$. Presumably, in practice firm $S$ typically does not have higher bargaining power than firm $L$, which means that it would be required to make cash payments, which is not observed in the data. This is perhaps either because a limited liability constraint is adopted, that is, the payment to firm $S$ is required to be non-negative, or it pays indirectly, by additional investments into the project. Let us also mention that Figure 7 also shows that the time of entry in the project (corresponding to value $X_{\tau}=x$ ), changes very little with bargaining power. 


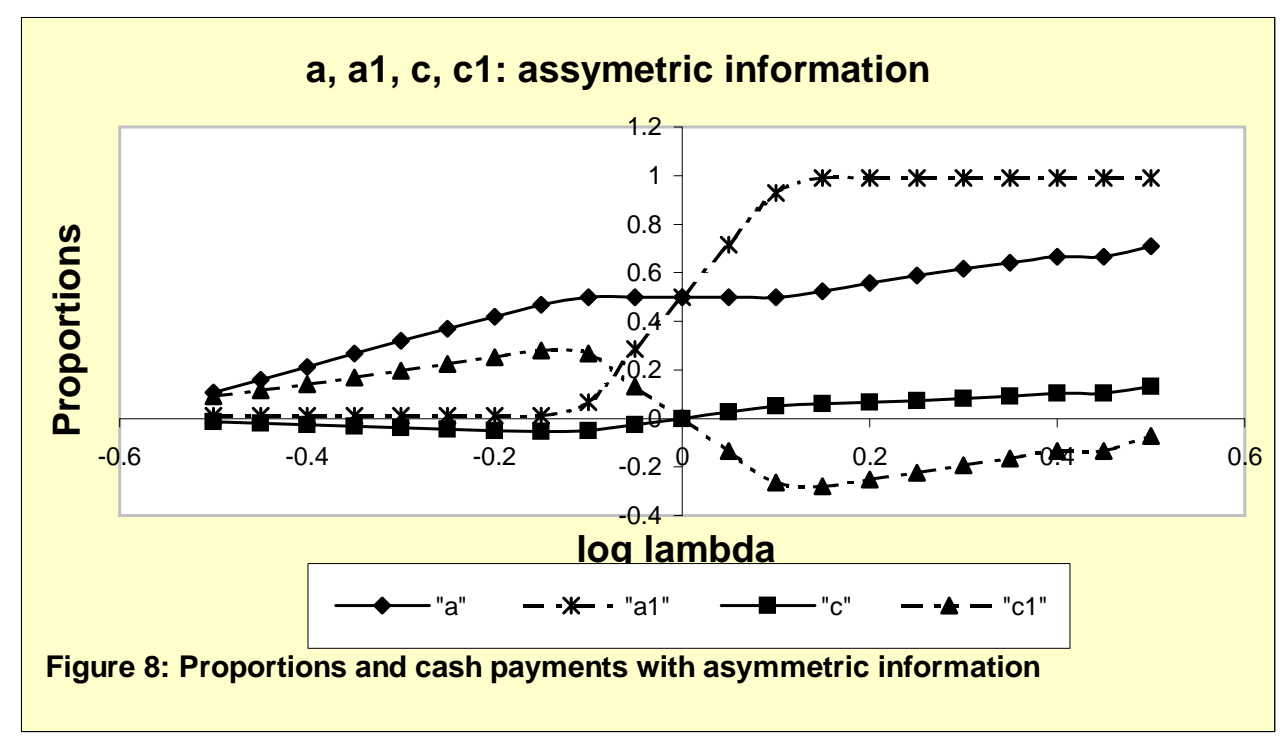

With asymmetric information and four contract parameters $a, a_{1}, c, c_{1}$ we see from Figure 8 that the situation changes quite a bit. The parameters $a$ and $a_{1}$ differ more among themselves, as do $c$ and $c_{1}$. Values of $a$ are less "sticky" than with symmetric information, but more than with two parameter contracts (Figure 5.) For high bargaining power of firm $S$, the firm gets paid the maximum initial percentage $a_{1}$, but, in return, it has to make initial cash payments to firm $L$, unlike in the symmetric information case where payments were received by firm $S$ with high bargaining power.

Assuming that in practice we are mostly in the low range of bargaining power for firm $S$, we could expect to see some initial positive cash payments to it. (In fact, we do see them, but it is hard to distinguish between those which are fixed cash payments and those which are a function of the stage of the project when the joint venture is entered.) Actually, it might be argued that what we see in Figure 8 on the low, but not too low bargaining power side, is what we see in many biothech/pharma co-development alliances: $c$ close to zero - no future cash payments, $c_{1}$ positive - some initial cash payments, $a$ close to $50 \%-$ equal split of royalties, $a_{1}$ positive - some initial payment in equity. Let us also mention, without providing a graph, that, relative to the symmetric information case, in this regime, the firm $S$ waits longer with low bargaining power and less with high bargaining power. However, these deviations are not of significant size - the time of entry is not that far from one with symmetric information. 
Varying $b, 4$ parameters. We find that with lower $b$ :

- $a$ is lower than with higher $b$ for low bargaining power, and higher for higher bargaining power. Same for $a_{1}$, except the effect is visible only when the bargaining power of the two firms is similar.

- initial cash payment $c$ is higher, while the future cash payment $c_{1}$ is lower (no matter which party pays).

- the firm $S$ enters sooner, and otherwise the timing effects are as in the case with two parameter contracts.

\section{Varying $\sigma, 4$ parameters.}

We find that with higher $\sigma$ :

- $a$ is higher than with lower $\sigma$ for low bargaining power, and lower for higher bargaining power. $a_{1}$ is lower, but the effect is visible only when the bargaining power of the two firms is similar.

- $c$ is lower than with lower $\sigma$ for low bargaining power, and higher for higher bargaining power. Other way round for $c_{1}$.

- as could be expected, higher $\sigma$ means waiting longer to enter.

- relative ratio of initial entry levels becomes lower, for low bargaining power, and higher, for high bargaining power.

Varying risk aversions $\gamma_{i}, 4$ parameters. As could be expected, with lower risk aversion $\gamma_{S}, a$ and $a_{1}$ become higher. So does $c_{1}$, while $c$ becomes lower on the low bargaining side. The time of entry does not change much. It is later for low bargaining side and sooner for high bargaining side. Relative ratio of initial entry levels is higher for low bargaining side and lower for high bargaining side.

Finally, we also graph the loss relative to the full information case and the ratio of initial $x$ values. 

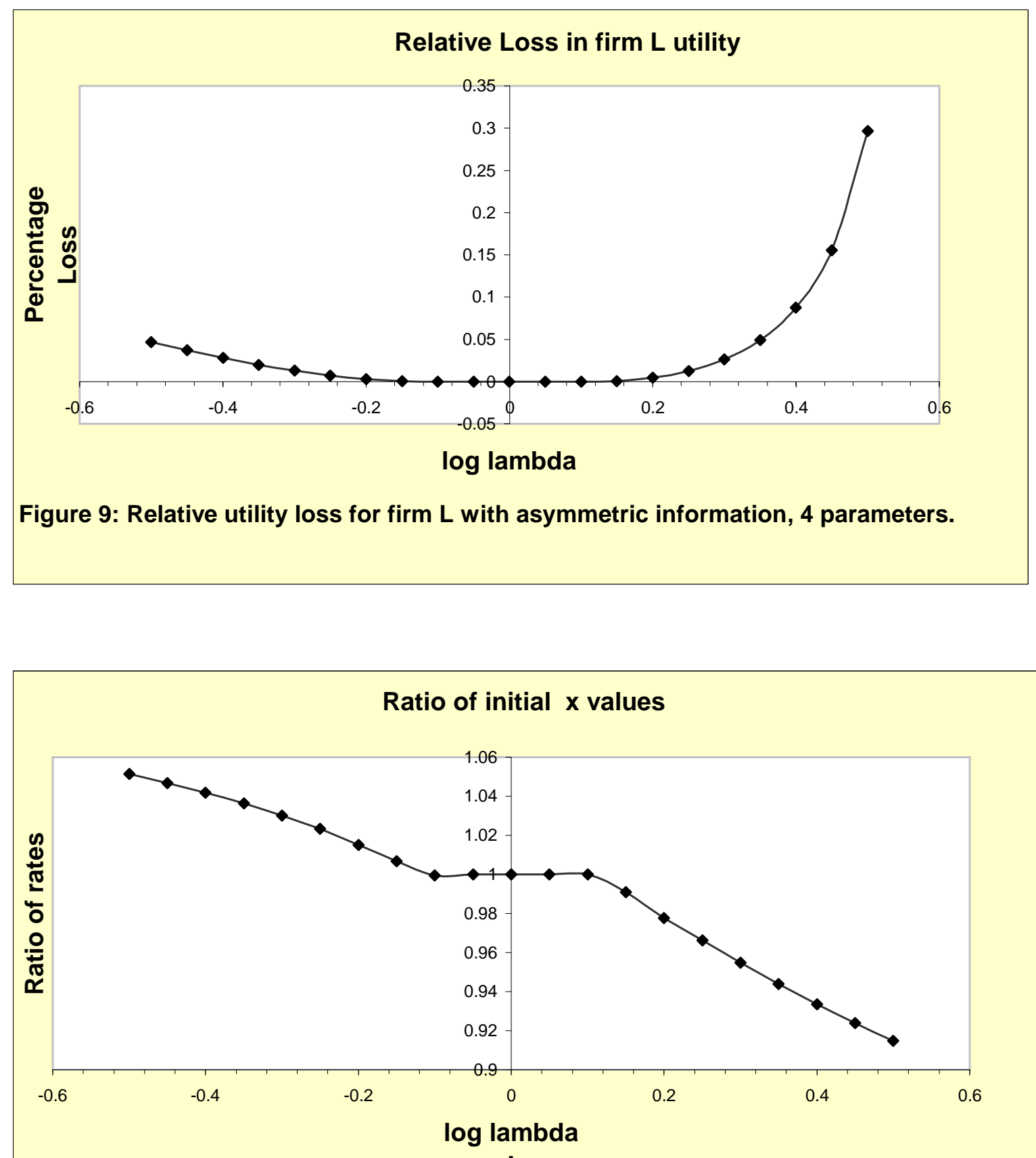

Figure 10: Ratio of initial $x$ values, symmetric relative to asymmetric information case, 4 parameters.

Qualitatively, the shape does not change much relative to the case of no fixed cash payments. However, the relative loss is significantly higher when the bargaining power of firm $S$ is high. Similarly, the ratio of entry time levels is lower for the high bargaining power, although, there is less variation with similar bargaining power. 


\section{Empirical results}

In this section we check some qualitative features of our model against the real world data. We use the data on alliances from Recombinant Capital (www.recap.com). We choose the alliances classified as co-developments where the $\mathrm{R} \& \mathrm{D}$ originator is a biotech firm and the other partner is a pharmaceutical firm. We allow that the alliance, in addition to codevelopment, includes other activities such as licensing, co-marketing, etc. Our database spans the years 1984-2003. As in Pisano (1997), in the cases where the same molecule is being developed for multiple therapeutic applications (e.g. cancer, infectious diseases, cardiovascular diseases, etc.), each application is treated as a separate project. Let us emphasize that we use the data not for exact empirical estimations, but, rather, to show that our model addresses realistic issues and gives consistent insights into alliance decisions.

Our results on the terms of the contracts are expressed as a function of the bargaining power of the firm $S$ (the biotech firm). To operationalize this concept, we use a proxy variable which we define as the number of prior alliances. The rationale behind this is that the more experienced the biotech firm is, the better it is able to negotiate and has a higher bargaining power. On the other hand for the inexperienced firms (such as the new entrants) we would expect that their negotiation leverage is lower, that they have a lower bargaining power. As the average number of alliances in our sample is 20.7 (with standard deviation of 23), we define the firms with less then 5 alliances as inexperienced (therefore having low bargaining power), and we define those with more that 35 alliances as experienced (thus having high bargaining power). There are 60 firms in the first group and 52 firms in the second group. When we exclude the cases in which both the royalty and the equity are unreported, we are left with 53 firms in the first group and 39 in the second group.

We find that the inexperienced firms have larger percentage of alliances signed in the preclinical phase (68.1\% vs. $56 \%$ for experienced firms), which is consistent with the argument that their utility of entering the alliances early is larger than for other firms, as postulated in Nicholson et al (2003). Regarding the royalty and equity arrangements, we find that the inexperienced firms are more likely to contract on royalty only (Table 1). This supports our findings expressed in Figures 2,5,6 and 8, that for the low bargaining 
power royalty is the prevailing instrument (in fact, in the low range, equity is mostly zero in Figures 6 and 8). For the experienced firms the data shows that equity is the more important instrument, which supports our findings that the higher bargaining power goes together with larger equity (Figures 2,5,6 and 8 again).

\section{Table 1}

\section{Contract terms depending on firm experience}

\begin{tabular}{lrrr} 
& Royalty only & Equity only & Both royalty and equity \\
\hline Inexperienced firms & $50.9 \%$ & $28.3 \%$ & $20.7 \%$ \\
Experienced firms & $33.3 \%$ & $41.0 \%$ & $25.6 \%$ \\
\hline
\end{tabular}

Similarly, in Table 2 we see that the experienced firms receive larger equity than those with less experience, which is again consistent with our predictions. (However, without the outliers, consisting of seven applications of the same molecule, the difference, while there, is not statistically significant.)

\section{Table 2}

\section{Average equity}

\begin{tabular}{ll} 
& \multicolumn{1}{c}{ Average equity } \\
\hline Inexperienced firms & 12.65 \\
Experienced firms & 292.7 (29.2 without outliers) \\
\hline
\end{tabular}

A further validation of the model is that we find evidence of "sticky" royalties, confirming the predictions from our theoretical models. Examining our database shows that among all the co-development alliances between a biotech company in the role of a $\mathrm{R} \& \mathrm{D}$ originator and a partnering pharma company, the royalties that range between $40 \%$ and $60 \%$ appear in $51.5 \%$ of the contracts. In particular, the royalties of exactly $50 \%$ appear in $42.3 \%$ of the contracts. Our models explain the "stickiness" of royalties either as a consequence of asymmetric information and the extra benefit of entering early (Figure 6), or as a consequence 
of using all the contracting instruments - royalties, equity, initial cash payments and future cash payments (Figures 7 and 8). When the contracts do not involve any kind of cash payments, we would expect the royalties not to go below $50 \%$ regardless of how small the bargaining power is (Figure 6). However, since in reality most contracts between pharma and biotech companies involve cash payments (in fact, they can be especially crucial for inexperienced companies which might lack resources for development), the cases described by Figures 7 and 8 may be more relevant. In addition to sticky royalties, it is evident from Figure 8 (asymmetric information) that the prediction is that the royalties rise somewhat with the bargaining power. We find confirmation in the data that the inexperienced firms are, indeed, paid smaller royalties: $34.2 \%$ of the inexperienced firms receive royalties of less than $20 \%$, while that is true for only $17.4 \%$ of the experienced firms. That is, larger bargaining power implies larger royalties, consistent with the theoretical implications shown in Figure 8. (However, again, the difference is not statistically significant if we take out the outliers.)

\section{Conclusions}

In this paper we use real options theory to model the decision of two (potentially risk averse) firms to enter a co-development alliance, where one firm is the project originator. Methodologically, we use the theory of the optimal stopping of diffusion processes. We consider both the case of symmetric information between the two firms, and the asymmetric information case in which one firm, called $S$, has complete knowledge about the project, but the other firm, called $L$, does not. In the latter case we assume that firm $S$ decides on the initiation time, while firm $L$ decides on how to share the profits. We determine the optimal entry times in both the symmetric and the asymmetric case.

When the contract does not include fixed cash payments, we find that in both cases the royalties and the up-front, equity payments increase with firm $S$ 's bargaining power. When this power is smaller than firm $L$ 's power (as is often the case), firm $L$ offers royalties that are larger than the equity payments. In case when firm $S$ has larger bargaining power than firm $L$, the equity payments become higher than royalties. However, if we assume 
that firm $S$ enjoys extra utility from alliance (as in the cases when the alliance with firm $L$ sends a positive signal about firm $S$ 's quality to future partners/investors), the situation changes significantly and we observe that the royalties become "sticky", i.e. firm $L$ offers the same profit percentage to firms of various bargaining power, as long as the latter is low. The (approximate) optimality of $50 \%$ royalties also occurs in the case of symmetric information and fixed cash payments allowed in the contract, as well as in the case of asymmetric information, fixed cash payments allowed, and comparable bargaining power of the two firms. Thus, our model offers explanations for a real world phenomenon seen in the biotechnology/pharmaceutical co-development contracts where royalties of around $50 \%$ are very common.

Another empirical fact also present in our theoretical models is that the firms with lower bargaining power (less experience) are paid more by royalties than by equity.

We also examine the sensitivity to project quality and find that in many cases the parameters of the optimal contract do not change much when project quality changes, which indicates that the contract offered is quite robust. This is in line with the prevalence of the same type of contracts in biotechnology/pharmaceutical co-developments. With higher project quality firm $S$ waits longer, in order to achieve higher level of initial profits. However, the relative ratio of initial entry levels between symmetric and asymmetric information does not change much. As could be expected, project uncertainty and risk aversion both cause delays in entering co-developments.

It would be of significant interest to extend our analysis to the following cases:

- Moral hazard risk coming from uncertainty about firm $L$ 's commitment to the project. One way to model this is to replace the project quality parameter $b$ with $b+e$, where effort $e$ is controlled by firm $L$, but unobserved by firm $S$. This would mean solving a problem of optimal contracting with moral hazard and optional entry time, something which has not been done in general. ${ }^{3}$ Similarly, we could assume that firm $S$ controls $b$.

- Modeling optimal time of exit. This would then encompass the excellent idea of Savva and Scholtes (2007) to include opt-out options in order to increase the efficiency of contracts.

\footnotetext{
${ }^{3}$ However, see Cvitanić, Wan and Zhang (2008) for moral hazard problems with optional exit time.
} 
We leave the analysis of these ambitious modeling frameworks for future research.

\section{Appendix}

Lemma 7.1 We have

$$
E_{x}\left[\int_{\tau}^{\tau+T} e^{-r s} h\left(X_{s}\right) d s\right]=E_{x}\left[e^{-r \tau} E_{X_{\tau}} \int_{0}^{T} e^{-r u} h\left(X_{u}\right) d u\right]
$$

Proof: Directly from

$$
\begin{aligned}
E_{x}\left[\int_{\tau}^{\tau+T} e^{-r s} h\left(X_{s}\right) d s\right] & =E_{x}\left[e^{-r \tau} E_{\mathcal{F}_{\tau}} \int_{0}^{T} e^{-r u} h\left(X_{\tau+u}\right) d u\right] \\
& =E_{x}\left[e^{-r \tau} E_{X_{\tau}} \int_{0}^{T} e^{-r u} h\left(X_{u}\right) d u\right]
\end{aligned}
$$

Consider the problem

$$
V(x)=\sup _{\tau} E_{x}\left[\mathbf{1}_{\{\tau<\infty\}} e^{-r \tau} g\left(X_{\tau}\right)\right]
$$

where

$$
d X_{t}=X_{t}\left[b d t+\sigma d W_{t}\right]
$$

and we have $r>0, r>b$. Denote

$$
\mathcal{L} f(x)=\frac{1}{2} \sigma^{2} x^{2} f^{\prime \prime}(x)+b f^{\prime}(x)-r f(x)
$$

\section{Assumption 7.1}

- (i) $g \in C^{2}((0, \infty))$

- (ii) There exists a unique $x^{*}>0$ such that $q\left(x^{*}\right)=0$ where

$$
q(x):=n g(x)-x g^{\prime}(x)
$$


Moreover, $q(0)<0$.

- (iii) $\mathcal{L} g(x) \leq 0, \quad x>x^{*}$

- (iv) $\left[x g^{\prime}(x)\right]^{2} \leq C\left(1+x^{j}\right)$, for some $j \geq 1, \quad x>x^{*}$

- (v) $E_{x}\left[\mathbf{1}_{\{\tau<\infty\}} e^{-r \tau}\left|g\left(X_{\tau}\right)\right|\right]<\infty$ for all stopping times $\tau$ and all $x>0$.

- (vi) $\lim _{T \rightarrow \infty} E_{x}\left[e^{-r T}\left|g\left(X_{T}\right)\right|\right]=0$

Define

$$
A:=\frac{g\left(x^{*}\right)}{\left(x^{*}\right)^{n}}
$$

and the function $w$ by

$$
\begin{aligned}
& w(x)=A x^{n}, \quad x<x^{*} \\
& w(x)=g(x), \quad x \geq x^{*}
\end{aligned}
$$

It is easily verified that $w \in C^{1}((0, \infty)) \cap C^{2}\left((0, \infty) \backslash\left\{x^{*}\right\}\right)$.

Theorem 7.1 Under Assumption (7.1), we have

$$
w(x)=V(x)
$$

and the optimal stopping time is

$$
\hat{\tau}=\inf \left\{t \geq 0 \mid X_{t} \geq x^{*}\right\}
$$

Proof: Note that

$$
\mathcal{L} w(x) \leq 0, \quad x>0
$$

We also want to show that

$$
w(x) \geq g(x), \quad x<x^{*}
$$

By definition of $w$ and $A$ this is equivalent to

$$
\frac{g\left(x^{*}\right)}{\left(x^{*}\right)^{n}} \geq \frac{g(x)}{(x)^{n}}, \quad x \leq x^{*}
$$


We have

$$
\frac{d}{d x}\left(\frac{g(x)}{(x)^{n}}\right)=-\frac{q(x)}{(x)^{2 n}}
$$

However, since $x^{*}$ is the unique solution of $q(x)=0$ and $q(0)<0$, we see that the above derivative is positive for $x<x^{*}$, which proves (7.17).

Next, define

$$
\tau_{k}=\inf \left\{t \geq 0 \mid X_{t} \leq 1 / k\right\}
$$

Fix $T>0$. By Ito's rule,

$$
e^{-r\left(\tau \wedge \tau_{k} \wedge T\right)} w\left(X_{\tau \wedge \tau_{k} \wedge T}\right)=w(x)+\int_{0}^{\tau \wedge \tau_{k} \wedge T} e^{-r s} \mathcal{L} w\left(X_{s}\right) d s+M_{\tau}^{k, T}
$$

where

$$
M_{t}^{k, T}=\int_{0}^{t \wedge \tau_{k} \wedge T} e^{-r s} \sigma X_{s} w^{\prime}\left(X_{s}\right) d W_{s}
$$

We have

$$
\begin{aligned}
E\left[\int_{0}^{T}\left[e^{-r s} \sigma X_{s} w^{\prime}\left(X_{s}\right)\right]^{2} \mathbf{1}_{\left\{s \leq \tau_{k}\right\}} d s\right] & \leq \sup _{x \in\left[1 / k, x^{*}\right]}\left[\sigma x w^{\prime}(x)\right]^{2} T+E\left[\int_{0}^{T}\left[\sigma X_{s} w^{\prime}\left(X_{s}\right)\right]^{2} \mathbf{1}_{\left\{X_{s}>x^{*}\right\}} d s\right] \\
& \leq \sup _{x \in\left[1 / k, x^{*}\right]}\left[\sigma x w^{\prime}(x)\right]^{2} T+C\left(T+\int_{0}^{T} E\left[X_{t}^{j}\right] d t\right) \\
& <\infty
\end{aligned}
$$

This means that $M^{k, T}$ is a martingale, and that $E\left[M_{\tau}^{k, T}\right]=0$. This implies, taking expectations in (7.18), using $\mathcal{L} w \leq 0, w \geq g$, that

$$
E\left[e^{-r \tau} g\left(X_{\tau}\right) \mathbf{1}_{\left\{\tau \leq \tau_{k} \wedge T\right\}}\right] \leq w(x)-w(1 / k) E\left[e^{-r \tau_{k}} \mathbf{1}_{\left\{\tau_{k} \leq T \leq \tau\right\}}\right]-E\left[e^{-r T} w\left(X_{T}\right) \mathbf{1}_{\left\{T<\tau_{k}<\tau\right\}}\right]
$$

Since $w(0)=0$, the middle term on the right-hand side converges to zero as $k \rightarrow \infty$. Moreover, since $0 \leq w(x) \leq C(1+|g(x)|)$, and because of Assumption 7.1 (vi), the last term converges to zero when $T \rightarrow \infty$. Finally, by Assumption 7.1 (v), we can use the dominated convergence theorem to conclude that the term on the left-hand side converges to $E\left[e^{-r \tau} g\left(X_{\tau}\right) \mathbf{1}_{\{\tau<\infty\}}\right]$. After taking expected value and the limits, we get $V(x) \leq w(x)$. 
If we now repeat the above $\operatorname{argument}$ with $\tau=\hat{\tau}$, we will see that everything holds as equality, hence $V(x)=w(x)$ and $\hat{\tau}$ is optimal.

\subsection{Verifying Assumption 7.1}

We consider the function

$$
g(x)=c_{0}+\sum_{i=1}^{I} c_{i} x^{\gamma_{i}} / \gamma_{i}
$$

for $x>0$, with $c_{i} \geq 0$ and at least one $c_{i}>0$ for $i \geq 1$. For those $i \geq 1$ with $c_{i}>0$ we also assume that all $\gamma_{i}$ are of the same sign, that we have $\gamma_{i} c_{0}<0$, and that $\theta_{i}>0$.

Obviously, $g^{\prime}>0, g^{\prime \prime}<0$. We can compute

$$
q^{\prime}=\left(n g-x g^{\prime}\right)^{\prime}=(n-1) g^{\prime}-x g^{\prime \prime}>0
$$

Also, we have $q(0)<0, q(\infty)>0$. Thus, there exists a unique $x^{*}$ such that $q\left(x^{*}\right)=0$. From this, and from

$$
q(x)=n c_{0}+\sum_{i} c_{i} x^{\gamma_{i}}\left(n / \gamma_{i}-1\right)
$$

we can compute

$$
n c_{0}=-\sum_{i} c_{i}\left(x^{*}\right)^{\gamma_{i}}\left(n / \gamma_{i}-1\right)
$$

We also have

$$
L(x):=\mathcal{L} g(x)=-\sum_{i} c_{i} x^{\gamma_{i}} \theta_{i} / \gamma_{i}-r c_{0}
$$

Note that

$$
L^{\prime}(x)=-\sum_{i} c_{i} x^{\gamma_{i}-1} \theta_{i}<0
$$

So, in order to prove $L(x) \leq 0$ for $x \geq x^{*}$, it is sufficient to show $L\left(x^{*}\right) \leq 0$. From the above expressions for $c_{0}$ and $L(x)$ we get

$$
\begin{aligned}
L\left(x^{*}\right) & =\sum_{i} c_{i}\left(x^{*}\right)^{\gamma_{i}}\left[r\left(\frac{1}{\gamma_{i}}-\frac{1}{n}\right)-\theta_{i} / \gamma_{i}\right] \\
& =\sum_{i} c_{i}\left(x^{*}\right)^{\gamma_{i}}\left[-\frac{r}{n}+\frac{1}{2}\left(\gamma_{i}-1\right) \sigma^{2}+b\right]
\end{aligned}
$$


Recalling the notation $\beta=2 b / \sigma^{2}$ and that $\gamma_{i}<1$, it is then sufficient to show

$$
n \beta-2 r / \sigma^{2} \leq 0
$$

Denote $\beta_{r}=2 r / \sigma^{2}$. Then the above is equivalent to

$$
\beta \sqrt{(\beta / 2-1 / 2)^{2}+\beta_{r}}<\beta_{r}+\beta^{2} / 2-\beta / 2
$$

or, after squaring

$$
\beta^{2}\left(\beta^{2} / 4-\beta / 2+1 / 4+\beta_{r}\right)<\beta_{r}^{2}+\beta^{4} / 4+\beta^{2} / 4+\beta^{2} \beta_{r}-\beta \beta_{r}-\beta^{3} / 2
$$

After cancelations, this boils down to

$$
0<\beta_{r}^{2}-\beta_{r} \beta=\beta_{r}\left(\beta_{r}-\beta\right)
$$

which is true, and we are done with proving (iii).

Assumption (iv) is straightforward. Next, we can easily see that

$$
e^{-r t} X_{t}^{\gamma} / \gamma=C e^{-\theta t} M_{t}
$$

where $M_{t}=\exp \left\{\sigma^{2} t / 2+\sigma W_{t}\right\}$ is a positive martingale with expectation equal to one. Then, (vi) follows immediately since $\theta>0$. Similarly, using Fatou's lemma and looking at a sequence $\tau \wedge N$ and letting $N \rightarrow \infty$, we also get (v).

\subsection{Exit and mixed entry/exit problem}

Following Johnson and Zervos (2008), we illustrate in this section how it is possible to transform exit problem and mixed entry/exit problem into a standard optimal stopping problem.

The general entry/exit problem is to maximize over the entry time $\tau_{0}$ and exit time $\tau_{1}$ 
the quantity

$$
E_{x}\left[\mathbf{1}_{\left\{\tau_{0}<\infty\right\}}\left(\int_{\tau_{0}}^{\tau_{1}} e^{-r t} h\left(X_{t}\right) d t+e^{-r \tau_{0}} h_{0}\left(X_{\tau_{0}}\right)\right)+e^{-r \tau_{1}} h_{1}\left(X_{\tau_{1}}\right) \mathbf{1}_{\left\{\tau_{1}<\infty\right\}}\right]
$$

Denote

$$
R_{h}(x)=E_{x} \int_{0}^{\infty} e^{-r s} h\left(X_{s}\right) d s
$$

Then, as in Lemma (7.1), the above is equivalent to the maximization problem

$$
w(x)=\sup _{\tau_{0}} E_{x}\left[\mathbf{1}_{\left\{\tau_{0}<\infty\right\}}\left\{e^{-r \tau_{0}}\left(\left[R_{h}+h_{0}\right]\left(X_{\tau_{0}}\right)-E_{X_{\tau_{0}}}\left[\left(e^{-r \tau_{1}}\left[R_{h}-h_{1}\right]\left(X_{\tau_{1}}\right)\right) \mathbf{1}_{\left\{\tau_{1}<\infty\right\}}\right]\right)\right\}\right]
$$

In the pure exit problem we have $\tau_{0}=0$. In this case the optimal $\tau_{1}$ is the first time $X$ goes below a level $X_{0}$. The value function can be written as

$$
v^{A}(x)=R_{h}(x)+\sup _{\tau_{1}} E_{x}\left[-e^{-r \tau_{1}}\left(R_{h}+h_{1}\right)\left(X_{\tau_{1}}\right) \mathbf{1}_{\left\{\tau_{1}<\infty\right\}}\right]
$$

The mixed entry/exit problem can then be written as

$$
\sup _{\tau_{0}} E_{x}\left[\left(e^{-r \tau_{0}}\left(\left[v^{A}-h_{0}\right]\left(X_{\tau_{0}}\right)\right) \mathbf{1}_{\left\{\tau_{0}<\infty\right\}}\right]\right.
$$

and is thus reduced to another classical optimal stopping problem.

\section{References}

[1] Akerlof, G. (1970) The Market for 'Lemons': Qualitative Uncertainty and the Market Mechanism. Quarterly Journal of Economics 84, 488-500.

[2] Amit, R., Glosten, L. and Muller, E. (1990) Entrepreneurial ability, venture investments, and risk sharing. Management Science 36 1232-1245.

[3] Bolton, P. and Dewatripont, M. (2005) Contract Theory. MIT Press.

[4] Borch, K. (1962) Equilibrium in a reinsurance market. Econometrica 30, 424-444. 
[5] Chesbrough, H. and Schwartz, K. (2007) Innovating Business Models With CoDevelopment Partnerships. Research Technology Management 50, 55-59.

[6] Comino, S., Mariel, P. and Sandons, J. (2007) Joint ventures versus contractual agreements: an empirical investigation. Span Econ Rev 9, 159-175.

[7] Crama, P., De Reyck, B. and Degraeve, Z. (2007). Milestone payments or royalties? Contract design for R\&D licensing. Working paper.

[8] Cvitanić, J., Wan, X. and Zhang, J. (2008) Principal-Agent Problems with Exit Options. The B.E. Journal in Theoretical Economics, 8, http://www.bepress.com/bejte/vol8/iss1/art23 .

[9] Dixit, A. K., and Pindyck, R. S. (1994) Investment under Uncertainty. Princeton University Press.

[10] Folta, T. B. (1998) Governance and uncertainty: The trade-off between administrative control and commitment. Strategic Management J. 19, 1007-1028.

[11] Folta, T. B. and Miller, K. (2002) Real options in equity partnerships. Strategic Management J. 23 77-88.

[12] Gallini, N. T. and Wright, B. D. (1990) Technology transfer under asymmetric information. The RAND Journal of Economics 21 147-160.

[13] Gulati, R. (1998) Alliances and networks. Strategic Management Journal 19, 293-317.

[14] Harrigan, K. (1988) Strategic Alliances and Partner Asymmetries. In: F. Contractor and P. Lorange 205-226.

[15] Hagedoorn, J. (1993) Understanding the rationale for strategic technology partnering: interorganizational models of co-operation and sectoral differences. Strategic Management Journal 14, 371-386.

[16] Hagedoorn, J. and Schakenraad, J. (1994) The Effect of Strategic Technology Alliances on Company Performance. Strategic Management Journal 16, 214-250. 
[17] Henderson, V. (2007) Valuing the Option to Invest in an Incomplete Market, Mathematics and Financial Economics 1, 103-128.

[18] Johnson, T.C. and Zervos, M. (2008) The explicit solution to a sequential switching problem with non-smooth data. Working paper, London School of Economics.

[19] Kogut, B. (1991) Joint Ventures and the Option to Expand and Acquire. Management Science 37, 19-33.

[20] Kogut, B. and Kulatilaka, N. (2001) Capabilities as real options. Organization Science $12744-758$.

[21] Mariti, P. and Smiley, R. (1983) Cooperative Agreements and the Organisation of Industry Journal of Industrial Economics 38, 183-198.

[22] McDonald, R. and Siegel, D. (1986) The Value of Waiting to Invest, The Quarterly Journal of Economics, 101, 707-728.

[23] McGrath, R. G. (1997) A real options logic for initiating technology positioning investments. Acad. Management Rev. 22, 974-996.

[24] Miao, J. and Wang, N. (2007) Investment, consumption, and hedging under incomplete markets. Journal of Financial Economics 86, 608-642.

[25] Miller, K. D. and Folta, T. B. (2002) Option value and entry timing. Strategic Management J. 23, 655-665.

[26] Mitchell, G. R. and Hamilton, W. F. (1988) Managing R\&D as a strategic option. Res.-Tech. Management 31, 15-22.

[27] Nicholson, S., Danzon P.M. and McCullough, J. (2005) Biotech-Pharmaceutical Alliances as a Signal of Asset and Firm Quality. Journal of Business 78, 1433-1464.

[28] Pisano, G.P. (1990) The R\&D Boundaries of the Firm: An Empirical Analysis. Administrative Science Quarterly 35, 153-176. 
[29] Pisano, G.P. (1997) R\&D performance, collaborative arrangements, and the marketfor-know- how: A test of the "lemons" hypothesis in biotechnology. Working paper.

[30] Porter, M. and Fuller, M. (1986) Coalitions and Global Strategy. In: M. Porter ed., Competition in Global Industries, Boston, HBS Press.

[31] Quinn, J.B. (2000) Outsourcing innovation: the new engine of growth. Sloan Management Review 41 , 13-28.

[32] Reuer, J. J. and Tong, T. W. (2005) Real options in international joint ventures. J. Management 31, 403-423.

[33] Rothaermel, F. (2001) Incumbent's advantage through exploring complementary assets via interfirm cooperation. Strategic Management Journal 22, 687-699.

[34] Teece, D. J. (1986) Profiting From Technological Innovation: Implications for Integrating, Collaborating, Licensing, and Public Policy. Research Policy 15, 285-305.

[35] Tripsas M. (1997) Unraveling the Process of Creative Destruction: Complementary Assets and Incumbent Survival in the Typesetter Industry. Strategic Management Journal 18, 119-142.

[36] Savva, N. and Scholtes, S. (2007) Double or quits: New Product Co-development with Opt-Out Options. Working paper.

[37] Veugelers, R. (1998) Collaboration In R\&D: An Assessment Of Theoretical And Empirical Findings. De Economist 146.

[38] Ziedonis, A.A. (2007), Real Options in Technology Licensing. Management Science 53, $1618-1633$. 